\title{
投石によるテングサの増殖効果に関して
}

\author{
加滕孝

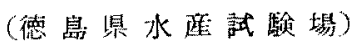

On the Effect of Stone and Concrete Collecters on the propagation of the Agar-agar Seaweed, Gelidium.

\section{Takashi Kato}

Sand stones, and pyramidal and prismatic concrete blocks were set as the cellecters of $\mathrm{Ge}$ lialum in the sea off the coast of Tokushima pref. in July, September and November, 1953.

Some of the collecters were recovered by divers for exammination on June 1, 1954, and the weight of Gelldium growing on each collecter was recorded. The data was analized statistically with the following results.

1) The weight of attaching Gelidiumt did not differ significantly on the stone and the collecters.

2) Gelfaium was found attaching on the collecters set in the three different months. Attachment was richest on the collecters set in July, and poorest on those set in November.

3) Geliaium attached on collecters far more abundantly on the shore facing the west and south than on the shore facing other directions.

4) Selecting suitable sites, therefore, is most important in propagating Gelidium by setting collecters.

\begin{abstract}
蝫震

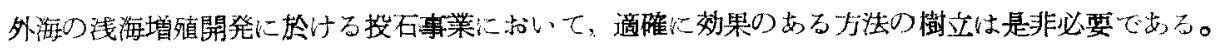

筆者小投石つ結果を判定する条件として，持期，場所，投石材の三要因を取揚げ，一定期間に施設し調査

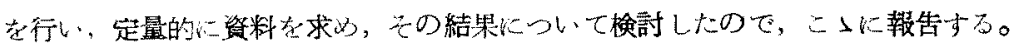

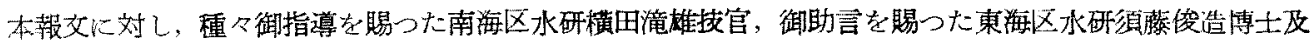

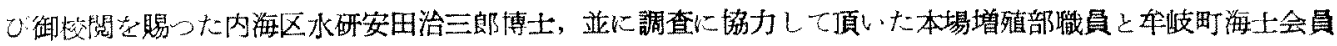
に対し犬マ感謝の意を表する。
\end{abstract}

\section{施設}

本研然に刘する施設は，テングサの增殖を目的として，海部郡车畦町地先海面に投石したるので，時期は 1953 年 7 月，9月，11月の 3 回。投柘として割石，三角柱と三触錐の人造石の 3 種, 場所は水落 (陸側)， 大身（北側），津島（南側），出羽島（西側）の4 地点（第1园）でむる。投石材の規格は第 1 表に示した。

Table 1. Specification of the collecters.

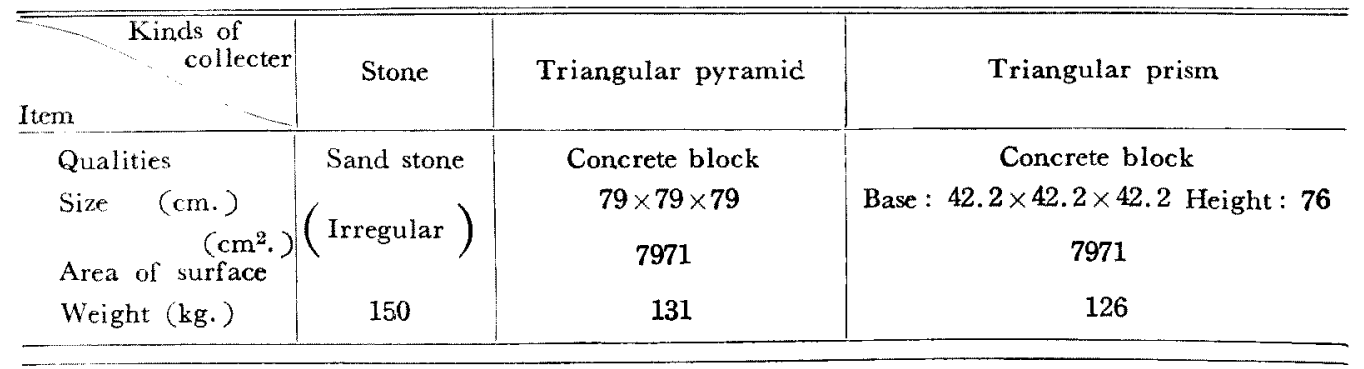

1955 年1月 18 日受理 
施設には各地点の投入日時の差を少なくする様心掛以た。投石後は潜水して石老配列し，石の重なるのを防 いだ。倘今回実施つ投石には，人工胞子付や親澡の巻付等は一划行わなかつた。割石々人造石の投入数形に 投入時の海況は第 2 表に示した。

Table 2. Description of the stations.

\begin{tabular}{|c|c|c|c|c|c|c|c|c|c|c|c|c|c|}
\hline \multirow[b]{2}{*}{$\begin{array}{l}\text { Date } \\
\text { of } \\
\text { selting }\end{array}$} & \multirow[t]{2}{*}{ Station } & \multicolumn{3}{|c|}{ Mizuochi } & \multicolumn{3}{|c|}{ Oshima } & \multicolumn{3}{|c|}{ Tsushima } & \multicolumn{3}{|c|}{ Tebashima } \\
\hline & & $\begin{array}{l}\text { Num } \\
\text { ber }\end{array}$ & Deptl & $\begin{array}{l}\text { Water } \\
\text { Temp }\end{array}$ & $\begin{array}{l}\text { Num- } \\
\text { ber }\end{array}$ & Depth & $\begin{array}{l}* \\
\text { Water } \\
\text { Temp. }\end{array}$ & $\begin{array}{l}\text { Num- } \\
\text { ber }\end{array}$ & Depth & $\begin{array}{l}\text { Water } \\
\text { Temp. }\end{array}$ & $\begin{array}{l}\text { Num- } \\
\text { ber }\end{array}$ & Deptl & $\begin{array}{l}\text { Water } \\
\text { Temp. }\end{array}$ \\
\hline $\begin{array}{c}1953 \\
46 \sim 10\end{array}$ & Stone & 100 & 15 & 24.2 & 100 & 15 & $\begin{array}{l}24.0 \\
24.3\end{array}$ & 50 & 5 & - & 50 & 5 & 23.6 \\
\hline & Stone & 150 & 11 & 26.5 & 100 & 12 & 26.8 & 75 & $\overline{5}$ & 27.0 & 75 & 4 & 27.2 \\
\hline V $4 \sim 6$ & $\begin{array}{l}\text { Triangular } \\
\text { pyramica }\end{array}$ & 12 & 9 & 26.9 & 13 & 11 & 27.2 & 12 & 4 & 26.8 & 13 & 4 & 26.8 \\
\hline & $\begin{array}{l}\text { Triangular } \\
\text { prism }\end{array}$ & 13 & 9 & 26.9 & 12 & 11 & 27.2 & 13 & 4 & 26.8 & 12 & 4 & 26.8 \\
\hline$\times \frac{129-}{30}$ & Stone & 130 & 5 & 20.8 & 120 & 7 & 21.8 & 68 & 5 & 22.2 & 180 & 5 & 17.8 \\
\hline
\end{tabular}

* Measured when the collecters were set.

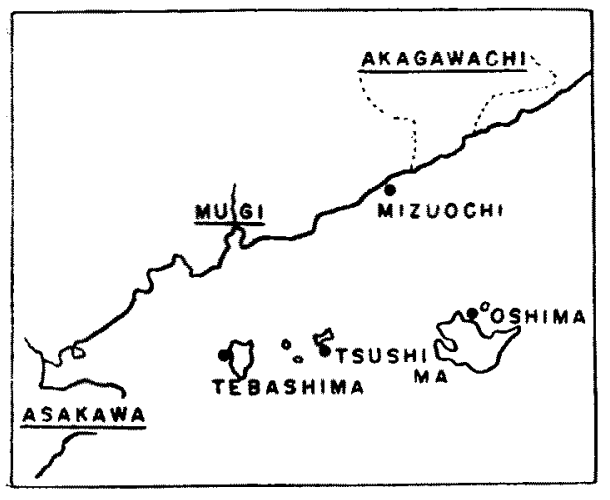

Fig. 1. Stations where the collecters were set.

\section{用真方法}

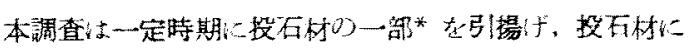

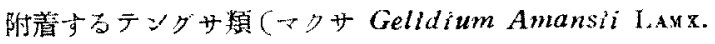

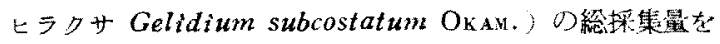

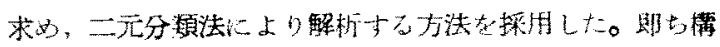

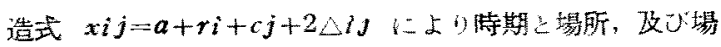

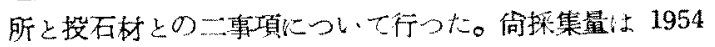

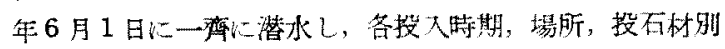

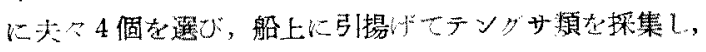

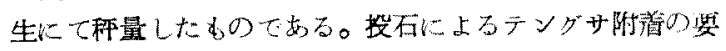

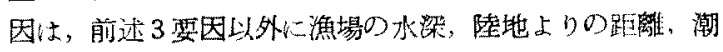

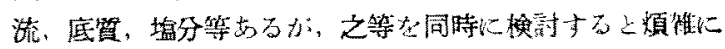
なるのて，今回俚全部無視した。

\section{桔}

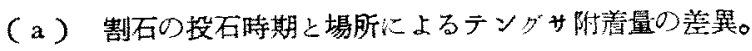

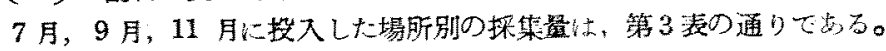

Table 3. Amount of Geltdium grown on the collecters (in grams).

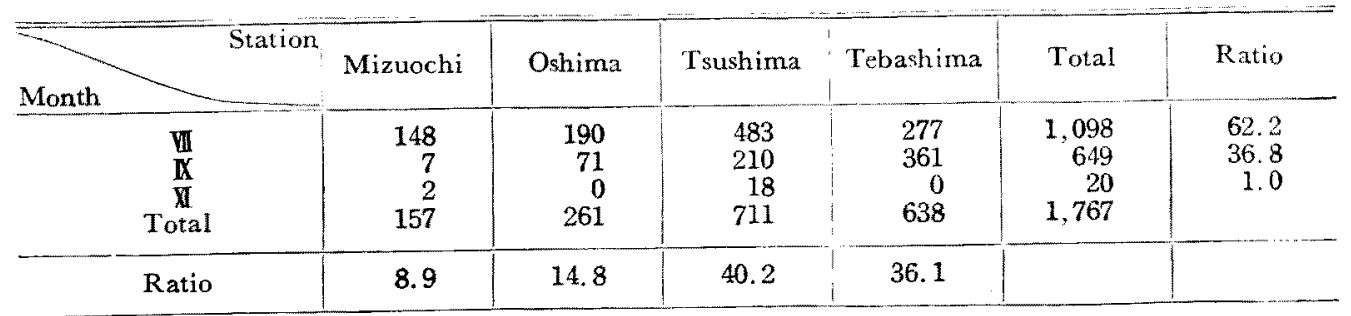

Note: Sum for four collecters.

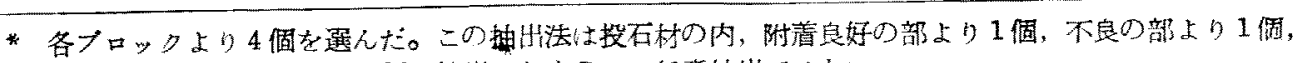

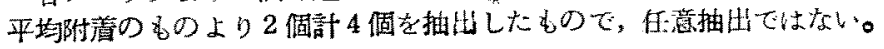




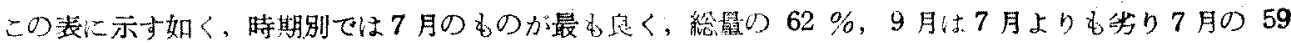

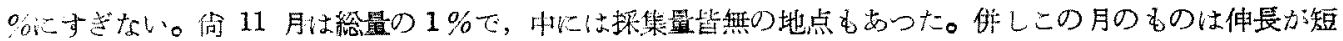

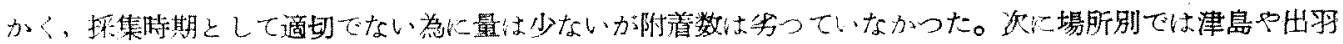

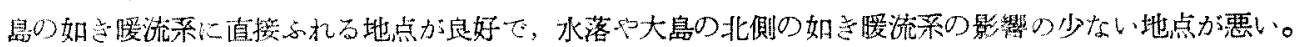

次に第 3 表小ら投入時期別，場所別の二元分類法に上り解析した結果，第 4 装安得た。即らこの表から割 石り投石で時期的に差が虫められたが，場所別には差が琶められなかかた。

Table 4. Analysis of variance of the amount of Gelidium grown on the collecters set at different seasons and stations.

\begin{tabular}{l|c|c|c|c}
\hline Source of variation & Sum of squares & Degree of fredom & Mean squares & Remarks \\
\hline Station & $74,920.92$ & $4-1$ & $24,973.64$ & $F_{0}<F(\alpha=0.05)$ \\
Month & $146,610.50$ & $3-1$ & $73,305.25 *$ & $F_{0}>F(\alpha=0.05)$ \\
Interaction & $66,138.90$ & $(3-1)(4-1)$, & $11,023.15$ &
\end{tabular}

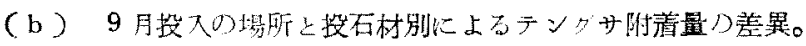

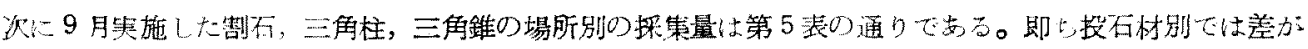

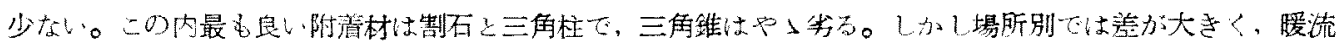

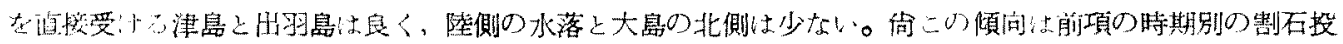
石結果上一致する。

Table 5. Amount of Geltdium grown on the collecters et in September.

\begin{tabular}{|c|c|c|c|c|c|c|}
\hline Collecter & Mizuochi & Oshima & Tsushima & Tebashima & Total & Ratio \\
\hline Stone & 7 & 71 & 210 & 361 & 649 & 35.5 \\
\hline $\begin{array}{l}\text { Triangular concrete } \\
\text { pyramid }\end{array}$ & 6 & 14 & 418 & 80 & 518 & 28.4 \\
\hline $\begin{array}{l}\text { Triangular concrete } \\
\text { prism }\end{array}$ & 2 & 55 & 513 & 80 & 659 & 36.1 \\
\hline Total & 16 & 140 & 1,141 & 529 & 1,826 & \\
\hline Ratio & 0.8 & 7.7 & 62.4 & 29.0 & & \\
\hline
\end{tabular}

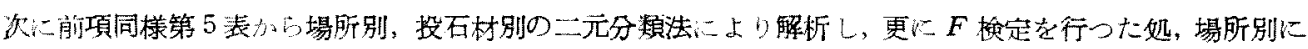

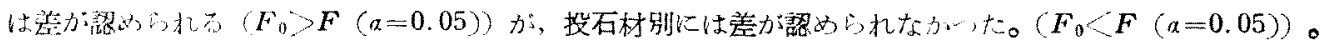

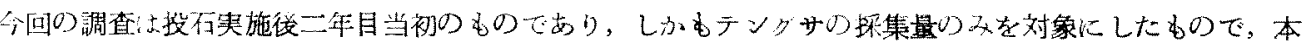

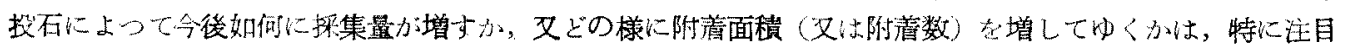

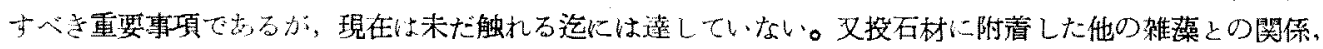

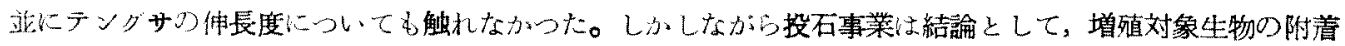

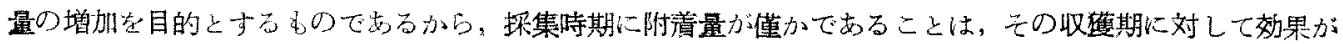

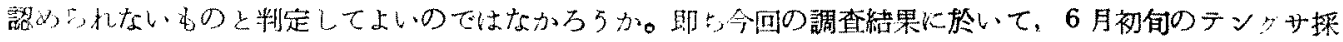
集盛期に 11 月投石材の如き附着量の悪いことは，投石の時期が不適と一応伴判定してもよいと考之られる。 (11 月投石材の最終效果心今後の調查に侯七決定したい)。

外投石材に就いてい調查結果上り特に選択少る必要がないと考えられ，高洒な人造石よりる割石て充分 目的が洋せら机ると思う。即七投石事業に対して最る重要な事項は，投石材の選択でなく投石場の選定にあ る。これイ゚去テングサの增殖場として必要なる条㤽の究明が第一に必要である5。

1953 年 7 月，9月，11 月の 3 期に亘り，徳島県海部郡车岐町地先のテングサ漁場に，割石と三角柱，三 


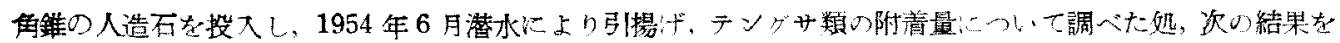
得た。

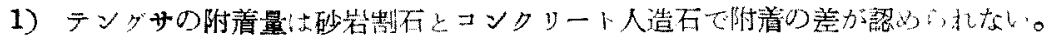

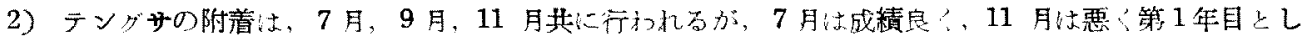
ては思わしくない。

3）テンダサ附着の場所別の盖は大きく，一般二西側苚側の漁場が良く，区対側は悪い。

4）投石には場所の選定が特に必要て支る。位って今後は場所の好適条件の究明に努め极ばならない。

$$
\text { 参考 女 献 }
$$

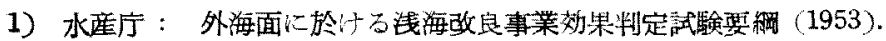

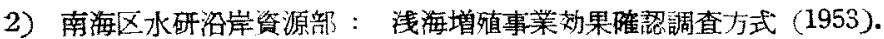

3) 三重水試：根付凟源増殖の為の新しい試 (1953).

4) 增山元三郎： 推計学いの道 東大出版部 (1951). 